\title{
Mutations analysis of BRCA1 gene in patients with breast cancer in South Khorasan province, East Iran
}

\author{
Ghazaleh Khalili-Tanha ${ }^{1}$, Ahmadreza Sebzari ${ }^{2}$, Mitra Moodi ${ }^{3}$, Fatemeh Hajipoor ${ }^{1}$, Mohsen Naseri*1
}

Received: 1 Sep 2018

Published: 2 Oct 2019

\begin{abstract}
Background: Breast cancer (BC) is well-known as the most common malignancy and the first leading cause of cancer-related death among women worldwide. Evidence suggests that familial history and age are important risk factors for the development of this disease in Iran. Mutations in BRCA1 and BRCA2 genes are the cause of 5 to $10 \%$ of hereditary BC. Recent studies demonstrated that mutations in BRCA1 were observed in high-risk women with family histories of BC. However, to date, the mutations have not been elucidated in BC patients from east of Iran. The purpose of this study was to analyze BRCA1 mutations in BC patient from South Khorasan Province.

Methods: In the present study, $88 \mathrm{BC}$ patients (11 positive family history) were screened for mutations in $B R C A 1$. The analysis of $B R C A 1$ was carried out by SSCP (single-strand conformation polymorphism) for shorter exons and direct sequencing in the case of longer ones.

Results: Twenty-eight of the patients (31.8\%) had a synonymous mutation (c.4308T $>$ C) in exon 13. A missense mutation (c. $4837 \mathrm{~A}>\mathrm{G}$ ) was presented in exon 16 with a frequency of $56.8 \%$. In exon 11 three missense mutations were observed, and the frequency rate for c. $3113 \mathrm{~A}>\mathrm{G}$ was $32.5 \%$, for c.3119G $>\mathrm{A}$ was $5 \%$, and the highest frequency belonged to c.3548A $>\mathrm{G}$ with $72.4 \%$ in familial BC and $45.4 \%$ in the non-familial group.

Conclusion: In our study, five mutations were found, but none of the founder mutations were identified in this population. Two missense mutations in exon $16(56.8 \%)$ and in exon 11 (65\%) had the highest frequency in South Khorasan Province.
\end{abstract}

Keywords: Breast Neoplasms, BRCA1 Gene, Single-Stranded Conformational Polymorphism (SSCP)

Conflicts of Interest: None declared

Funding: Birjand University of Medical Sciences

*This work has been published underCC BY-NC-SA 1.0 license.

Copyright $\subseteq$ Iran University of Medical Sciences

Cite this article as: Khalili-TanhaGh, Sebzari A, Moodi M, Hajipoor F, Naseri M. Mutations analysis of BRCA1 gene in patients with breast cancer in South Khorasan province, East Iran.Med J Islam Repub Iran. 2019(2 Oct);33:105.https://doi.org/10.47176/mjiri.33.105

\section{Introduction}

Breast cancer is considered as the most common malignancy as well as the second leading cause of mortality from cancer in women (1). The results of epidemiological studies show while the incidence and mortality rate of breast cancer has slightly decreased or stabilized in some developed countries like the US, the global incidence and mortality is increasing (2). There are many risk factors have been identified for breast cancer, among which age,

Corresponding author: Dr Mohsen Naseri, naseri@bums.ac.ir

1. Cellular and Molecular Research Center, Genomics research group, Birjand University of Medical Science, Birjand, Iran

2. Radiation Oncologist, Clinical Research Development Unit (CRDU), Valiasr hospital Birjand University of Medical Sciences, Birjand, Iran

3. Social Determinants of Health Research Center, Department of Health Education and Health Promotion, School of Health, Birjand University of Medical Sciences, Birjand, Iran gender (female), family history of breast cancer, geographic factors, race and ethnicity, reproductive history, and exposure to ionizing radiation are the most important and mentioned in lots of evidence (3).

Genetic factors play a decisive role in some cases of breast cancer. Cancer-causing genes categorized into three main types, including cellular proliferation inhibitors (tumor suppressors), proliferation activators (oncogenes),

\section{$\uparrow$ What is "already known" in this topic:}

The BRCA genes are known as tumor suppressor gene; they play a pivotal role in repairing DNA. There is a considerable relationship between BRCA mutations, which are reported in different exons and increasing risk of breast cancer.

\section{$\rightarrow$ What this article adds:}

The present study screening BRCA1 mutation in the east of Iran for the first time was shown that the observed mutations have no correlation with breast cancer, therefore are known as polymorphism. 
and those participating in DNA repair (4). It has been estimated that about 5-10 percent of breast cancer patients have inherited susceptibility genes. The familial tendency to develop breast and ovarian cancer is called "hereditary breast-ovarian cancer syndrome". A number of genes are associated with this syndrome; the best known is $B R C A$ mutations. $B R C A 1$ and $B R C A 2$ are two DNA repair genes in which hundreds of mutations have been reported. $B R C A$ mutations are associated with a significantly increased risk of breast cancer (5). Women inheriting BRCA1 or BRCA2 mutations experience $50-80 \%$ or $50 \%$ lifetime risk of breast cancer development, respectively (6). In patients with positive family history, screening of inherited gene mutations have been strongly recommended to determine a person's risk of acquiring the specific type of cancer. As mentioned before, $B R C A 1$ and $B R C A 2$ exhibited more than 2000 allelic mutations, most of which are deletions or nonsense or frameshift mutations. Thus, finding and characterizing frequent mutation in each population is required (7).

Despite little genetic studies regarding $B R C A$ mutations among breast cancer patients in Iran, to date, to the best of our knowledge, there is no clear information concerning the mutations of BRCA1 in the eastern part of Iran. Therefore, the aim of the present study was to determine the $B R C A 1$ alterations in 88 diagnosed breast cancer women from the eastern part of Iran (South Khorasan province).

\section{Methods \\ Subjects}

A total of 88 women diagnosed with breast cancer admitting to chemotherapy center of Birjand University of Medical Sciences (BUMS) from March 2016 to March 2017 were enrolled in the study. The study was approved by the Ethics Committee of Birjand University of Medical Sciences and with the 1964 Declaration of Helsinki and its later amendments or comparable ethical standards. Moreover, during the first visit, all patients provided written informed consent to participate in the present study. All patients were interviewed by trained interviewers (Oncologists), and their baseline demographics were recorded from their clinical charts. Furthermore, $5 \mathrm{ml}$ peripheral blood sample was collected from patients and stored at $20^{\circ} \mathrm{C}$ until use.

\section{Extraction of the genomic}

Blood samples were collected in EDTA-containing tubes, and genomic DNA was extracted from blood lymphocytes by using proteinase K/SDS digestion and saltingout extraction method (8). After measuring the DNA concentration and its purity by Nanodrop 2000 spectrophotometer (Thermo Scientific, Wilmington, DE), the genomic DNA was diluted to a final concentration of 50 $\mathrm{ng} / \mu \mathrm{l}$ in $\mathrm{dH}_{2} \mathrm{O}$ and stored at $4^{\circ} \mathrm{C}$ until subsequent analysis. These DNA samples were stored at $-70^{\circ} \mathrm{C}$ in the DNA bank of BUMS.

\section{PCR amplification of BRCA1 gene}

Primers specific to exon 2, 6, 13, 16, 20, 24 and partial of 11 , were designed by using Primer 3 online software and databases such as NCBI and UCSC (Table 1). PCR amplification was performed in a $35 \mu \mathrm{l}$ reaction containing $50 \mathrm{ng}$ genomic DNA, $3.5 \mu \mathrm{l} 10 \mathrm{X}$ buffer, $1.4 \mu \mathrm{l} \mathrm{MgCl}_{2}$ $(50 \mathrm{mM}), 0.3 \mathrm{mM}$ each forward and reverse primers (10PM), $0.7 \mu$ ldNTPs (10mM), $2.5 \mathrm{U}$ Taq DNA polymerase $(10 \mathrm{u} / \mu \mathrm{l})$ and $26 \mu \mathrm{l}$ of deionized $\mathrm{H}_{2} \mathrm{O}$.

PCR was performed with an Eppendorf (Mastercycler, Westbury, NY). The amplification conditions consisted of an initial denaturalization for $4 \mathrm{~min}$ at $94^{\circ} \mathrm{C} ; 35$ cycles of $30 \mathrm{sec}$ at $94^{\circ} \mathrm{C}$ and $30 \mathrm{sec}$ at the annealing temperature of each pair of primers; $30 \mathrm{sec}$ for elongation at $72^{\circ} \mathrm{C}$; and a final extension step of $10 \mathrm{~min}$ at $72^{\circ} \mathrm{C}$. The samples were maintained at $4^{\circ} \mathrm{C}$ until removal from the thermocycler. The presence of the PCR product was visualizedby electrophoresis at $1.5 \%$ agarose gel.

\section{SSCP analysis and Staining}

Non-radioactive SSCP was performed as follows: a $5 \mu \mathrm{l}$ volume of PCR product was denatured in $5 \mu$ l of formamide loading buffer (0.5 M EDTA, 95\% formamide and $0.05 \%$ bromophenol blue), at $95^{\circ} \mathrm{C}$ for $10 \mathrm{~min}$. In order to allow the fragments of ssDNA to fold into threedimensional structures as a result of intrastrand base pairing, the product immediately placed on ice. Denatured samples were loaded onto $10 \%$ acrylamide nondenaturation gel and electrophoresed at a constant $120 \mathrm{~V}$ at $4{ }^{\circ} \mathrm{C}$ for 20 hours then the gel was stained with silver nitrate and revealed with sodium carbonate.

\begin{tabular}{|c|c|c|c|c|}
\hline Exon no. & Nucleotide sequence & Annealing temperature $\left({ }^{\circ} \mathrm{C}\right)$ & Amplified fragment length (bp) & Technique \\
\hline \multirow[t]{2}{*}{2} & F: GACGTTGTCATTAGTTCTTTGG & 56 & 314 & SSCP-PCR \\
\hline & R: GGTCAATTCTGTTCATTTGC & & & \\
\hline \multirow[t]{2}{*}{6} & F: CGGTTTATACAGATGTCAATG & 52 & 311 & SSCP-PCR \\
\hline & R: CGTCATAGAAAGTAATTGTGC & & & \\
\hline \multirow[t]{2}{*}{11} & F: ATCACTGCAGGCTTTCCTGT & 59 & 900 & DS \\
\hline & R: GGGAAGCTCTTCATCCTCACT & & & \\
\hline \multirow[t]{2}{*}{13} & F:AATGGAAAGCTTCTCAAAGTA & 57 & 320 & SSCP-PCR \\
\hline & R:ATGTTGGAGCTAGGTCCTTAC & & & \\
\hline \multirow[t]{2}{*}{16} & F: AATTCTTAACAGAGACCAGAAC & 56 & 449 & SSCP-PCR \\
\hline & R: AAAACTCTTTCCAGAATGTTGT & & & \\
\hline \multirow[t]{2}{*}{20} & F: ATATGACGTGTCTGCTCCAC & 55 & 258 & SSCP-PCR \\
\hline & R: AGTCTTACAAAATGAAGCGG & & & \\
\hline \multirow[t]{2}{*}{24} & F: ATGAATTGACACTAATCTCTGC & 61 & 279 & SSCP-PCR \\
\hline & R: GTAGCCAGGACAGTAGAAGGA & & & \\
\hline
\end{tabular}

$\mathrm{SSCP}=$ Single-strand conformation polymorphism, DS=Direct sequencing 


\section{Sequencing of the polymorphism SSCP products}

The PCR products which had different pattern comparison with a healthy wild positive control pattern sent for sequencing determination (Biotech Company Kowsar, Iran, Tehran).

\section{Statistical Methods}

The genotype and allele frequency of $B R C A 1$ were tested for Hardy-Weinberg equilibrium (HWE) using PowerMarker V3.25. The relationship between family history and clinicopathological characteristics were tested using Fisher's exact test. Fisher's exact test was selected for statistical analyses due to the scarcity of mutations. All data were analyzed in SPSS statistical software version 22 and $\mathrm{P}<0.05$ was considered as statistical significance.

\section{Results}

In this cross-sectional study, a total of 88 DNA samples were collected from breast cancer diagnosed females, with or without a family history. The average age of patients was $46.28 \pm 9.85$ years, 27 patients had early breast cancer (younger than 40 years of age), and two of them were affected by bilateral breast cancer. Although family history plays an important role in breast cancer, only $12.5 \%$ of patients had a positive history. Results of pathologic information were showed that most of the patients $(81.4 \%)$ were affected with ductal carcinoma, and $98 \%$ of tumors were unilateral, including $60 \%$ right-sided tumors. The analysis did not reveal any significant differences between family history and clinicopathological characteristics such as age, menopause, smoking, type, and stage of cancer
(Table 2).

88 patientswere analyzedfor $B R C A 1$ gene mutations in exons 2, 6, 13, 20, and 24. Furthermore, a partial region of exon 11 (900 bp) was evaluated in 40 patients selected according to family history and early breast cancer (under 40 years old). These exons were selected based on several previous studies. These regions are considered as hotspots in the Iranian population (8). Following extraction of the DNA as previously described, mutations were detected by the SSCP technique, silver nitrate staining, and DNA sequencing (Fig. 1).

No mutations were observed in exon 2, 6, 20 and 24, but these have been identified five variants in this cohort: one synonymous mutation in exon 13 (c. $3113 \mathrm{~A}>\mathrm{G}$ ), four of which were missense, three of them were in exon 11 (c. $3113 \mathrm{~A}>\mathrm{G}$, c. $3119 \mathrm{G}>\mathrm{A}$, c. $3548 \mathrm{~A}>\mathrm{G})$, and one of them was in exon 16 (c. $4837 \mathrm{~A}>\mathrm{G}$ ). The mutations and allele frequencies are summarized in Tables 3 and 4.

\section{Discussion}

To the best of our knowledge, this is the first genetic study has been performed to evaluate BRCAl mutations among $\mathrm{BC}$ patients in the South Khorasan (East of Iran). Accordingly, 88 breast cancer diagnosed women with positive family history $(\mathrm{n}=11)$ or those without such a history ( $\mathrm{n}=77$ ) were evaluated to determine $B R C A 1$ mutations.

In the present study, the average age of cases was 48.2 years. A number of epidemiological studies have found that the average age of the patients in different parts of Iran is about 10-15 years lower than the western countries.

Table 2. Demographic and clinicopathological characteristics of patients

\begin{tabular}{|c|c|c|c|c|}
\hline \multirow[t]{2}{*}{ Characteristics } & \multicolumn{2}{|c|}{ Numbers (\%) } & \multirow[t]{2}{*}{ Total } & \multirow[t]{2}{*}{$\mathrm{p}$} \\
\hline & $\overline{\mathrm{FBC}}$ & NFBC & & \\
\hline Age groups (years) & & & & 0.69 \\
\hline$<40$ & $1(9.1)$ & $27(36)$ & $28(32.6)$ & \\
\hline$>40$ & $10(90.9)$ & $48(64)$ & $58(67.4)$ & \\
\hline Menopause & & & & 0.20 \\
\hline Positive & $8(72.7)$ & $37(49.3)$ & $45(52.9)$ & \\
\hline Negative & $3(27.3)$ & $38(50.7)$ & $41(47.1)$ & \\
\hline Smoking & & & & 0.67 \\
\hline Positive & $1(9.1)$ & $8(10.7)$ & $9(10.5)$ & \\
\hline Negative & $10(90.9)$ & $67(89.3)$ & $77(89.5)$ & \\
\hline Cancer type & & & & 0.60 \\
\hline Ductal carcinoma & $7(100)$ & $43(86)$ & $50(88.1)$ & \\
\hline Lobular carcinoma & $0(0)$ & $7(14)$ & $7(11.9)$ & \\
\hline Grade & & & & 0.46 \\
\hline I & $0(0)$ & $5(10.6)$ & $5(9.3)$ & \\
\hline II & $4(66.7)$ & $36(76.6)$ & $40(75.9)$ & \\
\hline III & $2(33.3)$ & $6(12.8)$ & $8(14.8)$ & \\
\hline Stage & & & & 0.28 \\
\hline I & $0(0)$ & $7(14)$ & $7(11.9)$ & \\
\hline II & $4(57.1)$ & $26(52)$ & $30(50.8)$ & \\
\hline III & $3(42.9)$ & $14(28)$ & $17(30.5)$ & \\
\hline IV & $0(0)$ & $3(6)$ & $3(6.8)$ & \\
\hline Estrogen receptors(ER) & & & & 0.39 \\
\hline Positive & $6(85.7)$ & $34(60.7)$ & $40(64.6)$ & \\
\hline Negative & $1(14.3)$ & $22(39.3)$ & $23(35.4)$ & \\
\hline Progesterone receptors (PR) & & & & 0.72 \\
\hline Positive & $3(42.9)$ & $31(58.5)$ & $34(56.5)$ & \\
\hline Negative & $4(57.1)$ & $22(41.5)$ & $26(43.5)$ & \\
\hline HRE2 & & & & 0.41 \\
\hline Positive & $3(42.9)$ & $14(25.5)$ & $17(26.6)$ & \\
\hline Negative & $4(57.1)$ & $41(74.5)$ & $45(73.4)$ & \\
\hline
\end{tabular}

FBC, Familial Breast Cancer; NFBC, Non-Familial Breast cancer. 
(a)
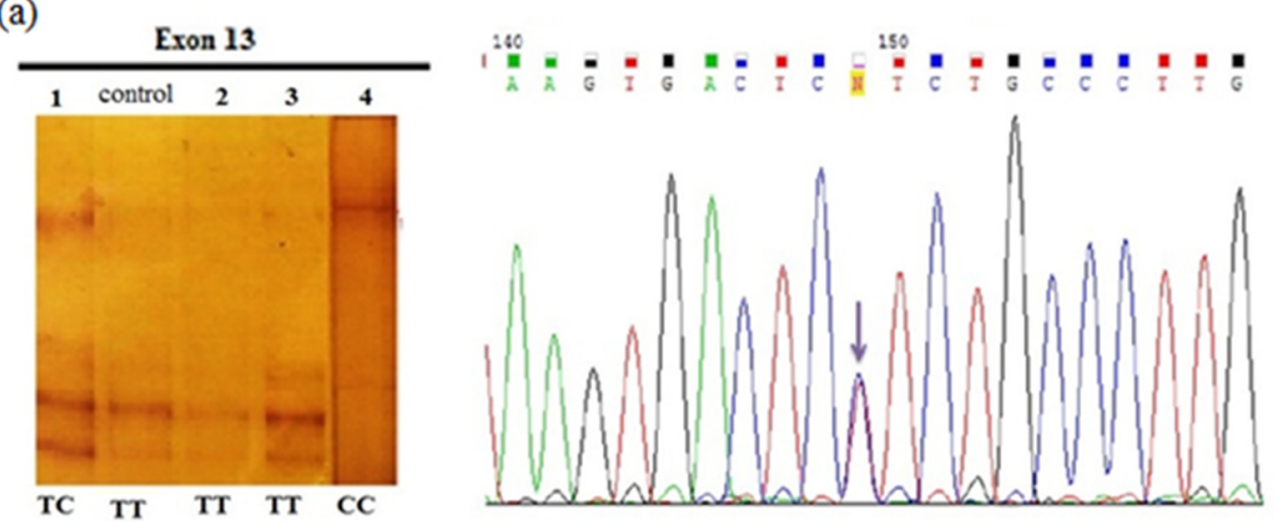

(b)

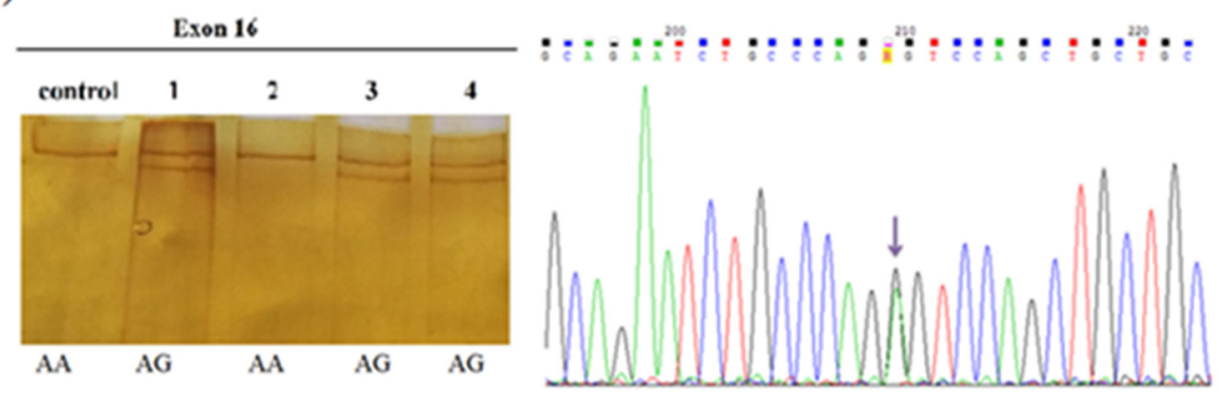

Fig. 1. Single-strand conformation polymorphism (SSCP) assay for a mutation in BRCA1, which were confirmed by direct sequencing. (a): Silverstained gel showing bands of exon 13, lanes 2 and 3 wild-type sequence, lane 1 heterozygous and lane 4 homozygous variant (c.4308T $>$ C). (b): Silver- stained gel showing bands of exon 16, lane 2 wild-type, lane 1, 3 and 4 heterozygous polymorphism (c. $4837 \mathrm{~A}>\mathrm{G}$ ).

\begin{tabular}{|c|c|c|c|c|c|c|c|c|}
\hline \multirow[t]{2}{*}{ Gene } & \multirow[t]{2}{*}{ Exon } & \multirow[t]{2}{*}{ Sequence variant } & \multirow[t]{2}{*}{ AA change } & \multirow[t]{2}{*}{ RefSNP } & \multirow[t]{2}{*}{ Mutation type } & \multicolumn{2}{|c|}{ Frequency } & \\
\hline & & & & & & $\mathrm{FBC}=11$ & $\mathrm{NFBC}=77$ & Total $=88$ \\
\hline \multirow[t]{6}{*}{ BRCA1 } & 13 & c. $4308 \mathrm{~T}>\mathrm{C}$ & Ser1436Ser & rs1060915 & Synonymous & $4(36 \%)$ & $24(32 \%)$ & $28(31.8)$ \\
\hline & 16 & c. $4837 \mathrm{~A}>\mathrm{G}$ & Ser1613Gly & rs 1799966 & Missense & $7(63.6)$ & $43(55.8)$ & $50(56.8)$ \\
\hline & & & & & & $\mathrm{FBC}=11$ & $\mathrm{NFBC}=29$ & Total $=40$ \\
\hline & 11 & c. $3113 \mathrm{~A}>\mathrm{G}$ & p.Glu1038Gly & rs 16941 & Missense & $2(18)$ & $11(37.9)$ & $13(32.5)$ \\
\hline & 11 & c. $3119 \mathrm{G}>\mathrm{A}$ & p.Ser1040Asn & rs4986852 & Missense & $0(0)$ & $2(7)$ & $2(5)$ \\
\hline & 11 & c. $3548 \mathrm{~A}>\mathrm{G}$ & p.Lys 1183Arg & rs16942 & Missense & $5(45.4)$ & $21(72.4)$ & $26(65)$ \\
\hline
\end{tabular}

FBC, Familial Breast Cancer; NFBC, Non-Familial Breast cancer; AA Change, Amino Acid Change

Table 4. Genotype and allele frequency of five distinct polymorphic sites of BRCA1 gene in breast cancer patients

\begin{tabular}{|c|c|c|c|c|c|}
\hline \multirow[t]{2}{*}{ Polymorphic sites } & \multicolumn{3}{|c|}{ Genotype frequenciesNumber (\%) } & \multicolumn{2}{|c|}{ Allele frequencies } \\
\hline & $\mathrm{W} / \mathrm{W}$ & $\mathrm{W} / \mathrm{V}$ & $\mathrm{V} / \mathrm{V}$ & $\mathrm{p}$ & $q$ \\
\hline Ex-11 (Glu1038Gly) & $27(67.5)$ & $13(32.5)$ & $0(0)$ & $67(83.8)$ & $13(16.2)$ \\
\hline Ex-11(Ser1040Asn) & $38(95)$ & $2(5)$ & $0(0)$ & $78(97)$ & $2(3)$ \\
\hline Ex-11 (Lys1183Arg ) & $14(35)$ & $14(35)$ & $12(30)$ & $42(52)$ & $38(48)$ \\
\hline Ex-13 (Ser1436Ser) & $60(68.2)$ & $16(18.2)$ & $12(13.6)$ & $136(77.3)$ & $40(22.7)$ \\
\hline Ex-16 (Ser1613Gly) & $38(43.2)$ & $50(56.8)$ & $0(0)$ & $126(71.5)$ & $50(28.5)$ \\
\hline
\end{tabular}

W/W, Wild type; W/V, Homozygote, mutant; V/V, Heterozygote; p, Normal allele; q, mutant allele.

Similar to our result, Heydari et al. have reported that the mean age of BC patient in the south of Iran was 46.3 years (9). Moreover, in a systematic review and meta-analysis study in which 52 studies with 332999 BC cases were included, the average age of Iranian patients was 48.59 years (10).

Mutations in exons 2, 6, 13, 16, 20, and 24 were screened by SSCP technique, and a $900 \mathrm{bp}$ fragment of exon 11 was analyzed by using direct sequencing. No mutation was observed in exon 2, 6, 20 and 24; whereas, a synonymous variation in exon 13 , a missense variation in exon 16, and three missense mutation were detected in exon 11. Although $185 \mathrm{delAG}$ and 5382insC mutations in exon 2 and 20 of $B R C A 1$ gene respectively are known as founder mutations which are frequently observed in Ashkenazi Jewish breast cancer patients, in the current study, there were neither new nor reported mutations in these exons (11). Numerous studies have reported these polymorphisms in other populations $(12,13)$. Our findings are in line with the previous report from the other parts of Iran. Fattahi et al. investigated the frequency of $185 \mathrm{delAG}$ and 5382 insC mutations in 55 women with a family histo-

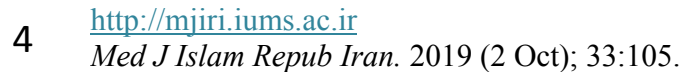


ry of BC and 250 sporadic patients in the south of Iran by a multiplex PCR technique; their results revealed that the above-mentioned mutations were not detected in their cases (14). Bar-Sade et al. performed a study on a group consists of 150 Iranian Jews, 354 of Moroccan origin, and 200 Yemenites to detect the prevalence of $B R C A 1$ founder mutation (185delAG). Four of Moroccan origin (about $1.1 \%$ ) and none of the Yemenites or Iranians have this mutation (15). However, some studies reported a low frequency of the $185 \mathrm{delAG}$ and $5382 \mathrm{insC}$ founder mutation in the $B R C A 1$ gene in Iranian breast cancer patients (1619). Accordingly, it seems that the incidence of $B R C A 1$ founder mutations is rareamong Iranian breast cancer.

In exon 13, a synonymous polymorphism (c. 4308T >C) was found in $36 \%$ of patients with familial breast cancer, and $32 \%$ of non-familial patients. This variant was documented in the 1000 Genomes project with a Reference SNP ID (rs1060915), and its frequency in Exome Sequencing Project (GO-ESP) was reported $27 \%$. The majority of studies found this mutation as a polymorphism with low frequencies (20-22). Ghaderi et al. have studied 80 patients in the central part of Iran, Fars province. They reported that the prevalence of polymorphism (c. $4308 \mathrm{~T}>\mathrm{C}$ ) was reported $36.4 \%, 50 \%$, and $13.6 \%$ respectively for wild, heterozygous, and homozygous genotype (23). Seo et al. evaluated BRCA1 mutations in 97 Korean patients with sporadic breast cancer and the polymorphism c. $4308 \mathrm{~T}>\mathrm{C}$ was observed in $30 \%$ of patients (24). Mundhofir et al. noted that the frequency of the heterozygous genotype of c. $4308 \mathrm{~T}>\mathrm{C}$ was $53.3 \%$ in Indonesian population (25).

Polymorphism (c. 4837A $>$ G) in exon 16, which changes serine to glycine, was observed in 50 patients ( 7 of them were women with family history, and 43 were sporadic). Reference SNP ID of c. $4837 \mathrm{~A}>\mathrm{G}$ was recorded as rs1799966 with the frequency of $29 \%$ in GO-ESP. Keshavarzi et al. investigated entire coding sequences and all intron/exon of BRCA1 genes in 85 patients. They reported this mutation as a polymorphism with a frequency of $21 \%(20)$. Also, Ghaderi et al. reported the prevalence of this mutation $50 \%$ and $13 \%$ for GG and AG genotypes respectively (23). Zhu et al. observed that rs1799966 (BRCA1) was significantly associated with pancreatic cancer $\mathrm{p}=0.0010$, and this mutation can mostly be regarded as a risk biomarker of pancreatic cancer through (26).

Three missense polymorphism (c.3113A $>\mathrm{G}$, c.3119G $>\mathrm{A}$, c.3548A $>\mathrm{G}$ ) were detected in exon 11. The frequency rate for c. $3113 \mathrm{~A}>\mathrm{G}$ was $32.5 \%$, for c. $3119 \mathrm{G}>\mathrm{A}$ was $5 \%$, and the highest frequency belonged to c. $3548 \mathrm{~A}>\mathrm{G}$ with $72.4 \%$ in familial breast cancer and $45.4 \%$ in non-familial breast cancer. The middle part of the protein encoded by exon-11 and more than half of the mutations occur in this exon (27). These variations (c. $3113 \mathrm{~A}>\mathrm{G}$, c. $3119 \mathrm{G}>\mathrm{A}, \quad$ c. $3548 \mathrm{~A}>\mathrm{G}$ ) are known as rs 16941 , rs4986852 and rs16942 in NCBI and their frequencies were reported $27 \%, 1 \%$ and $29 \%$ in the database GO-ESP, respectively. These mutations have been reported in previous studies $(20,23)$. Pietschmann et al. screened complete coding sequences and 3 ' and 5' UTR regions of $B R C A 1$ in Iranian population. The polymor- phism c. $3113 \mathrm{~A}>\mathrm{G}$, c. $3119 \mathrm{G}>\mathrm{A}$ and c. $3548 \mathrm{~A}>\mathrm{G}$ were respectively identified in $30 \%, 10 \%$ and $30 \%$ of patients (21). Zanella et al. analyzed $B R C A 1$ and $B R C A 2$ genes by Ion AmpliSeq panel, a type of next-generation sequencing (NGS), in Italian patients. The frequency of variations c. $3113 \mathrm{~A}>\mathrm{G}$, c. $3119 \mathrm{G}>\mathrm{A}$, c. $3548 \mathrm{~A}>\mathrm{G}$ were $53 \%, 10 \%$, and $53 \%$ separately (28).

There is a hypothesis that one of the functions of the $B R C A 1$ gene is regulation stem cells in breast tissue, in BRCA1 damaged cells this regulatory function fails and these cells lose their tight proliferative control. Many studies confirmed the correlation of BRCA gene with some marker of breast cancer stem cell. For instance, Madjd et al. showed that among various markers, increasing the expression of aldehyde dehydrogenase 1 (ALDH1) is inversely correlated with decreasing BRCA1 in breast tissue. Their research suggested that increasing the cells expressing ALDH1, because of knockdown of BRCA1 in breast epithelial cells, can be considered as a breast cancer prevention (29).

\section{Conclusion}

Our study concluded that $B R C A 1$ mutations are less frequent in patients with breast cancer who live in the East of Iran. Our results have confirmed previous evidence demonstrated that BRCA1 mutations are less common between Iranian patients. Therefore, extensive studies are needed to identify founder mutation to provide appropriate cancer prevention, screening, and counseling strategies based on the mutation data for the Iranian population.

\section{Acknowledgments}

This study was financially supported by the Birjand University of Medical Sciences, Iran. (Grant No, 1145). We thank all colleagues and participants in this research.

\section{Conflict of Interests}

The authors declare that they have no competing interests.

\section{References}

1. Siegel RL, Miller KD, Jemal A. Cancer statistics, 2016. CA Cancer J Clin. 2016;66(1):7-30

2. DeSantis CE, Fedewa SA, Goding Sauer A, Kramer JL, Smith RA, Jemal A. Breast cancer statistics, 2015: Convergence of incidence rates between black and white women. CA Cancer J Clin. 2016;66(1):31-42.

3. Kumar V, Abbas AK, Aster JC. Robbins Basic Pathology E-Book: Elsevier Health Sciences; 2017.

4. Cooper GM, Hausman RE. The cell: Sinauer Associates Sunderland; 2000.

5. BRCA SG. A strong candidate for the breast and ovarian cancer susceptibility gene BRCA1. Science. 1994;266:7.

6. Petrucelli N, Daly MB, Pal T. BRCA1-and BRCA2-associated hereditary breast and ovarian cancer.GeneReviews. University of Washington, Seattle. 2016.

7. Neamatzadeh H, Shiryazdi SM, Kalantar SM. BRCA1 and BRCA2 mutations in Iranian breast cancer patients: A systematic review. J Res Med Sci. 2015;20(3):284.

8. Naseri M, Sebzari A, Haghighi F, Hajipoor F, Razavi FE. Frequency of K-RAS and N-RAS Gene Mutations in Colorectal Cancers in Southeastern Iran. Asian Pac J Cancer Prev. 2016;17(9):4511-5.

9. Heydari ST, Mehrabani D, Tabei S, Azarpira N, Vakili M. Survival of breast cancer in southern Iran. Iran J Cancer Prev. 2009;2(1):51-4. 
10.YektaKooshali M, Esmaeilpour-Bandboni M, Sharemi S, Alipour Z. Survival Rate and Average Age of the Patients with Breast Cancer inIran: Systematic Review and Meta-Analysis. J Babol Uni Med Sci. 2016;18(8):29-40.

11.Levy-Lahad E, Catane R, Eisenberg S, Kaufman B, Hornreich G, Lishinsky E, et al. Founder BRCA1 and BRCA2 mutations in Ashkenazi Jews in Israel: frequency and differential penetrance in ovarian cancer and in breast-ovarian cancer families. Am J Med. Genet. 1997;60(5):1059.

12. Yazici H, Bitisik O, Akisik E, Cabioglu N, Saip P, Muslumanoglu $\mathrm{M}$, et al. BRCA1 and BRCA2 mutations in Turkish breast/ovarian families and young breast cancer patients. $\mathrm{Br} \mathrm{J}$ Cancer. 2000;83(6):737.

13.Sokolenko AP, Mitiushkina NV, Buslov KG, Bit-Sava EM, Iyevleva $\mathrm{AG}$, Chekmariova EV, et al. High frequency of BRCA1 5382insC mutation in Russian breast cancer patients. Eur J Cancer. 2006;42(10):1380-4.

14.Karimaghaee N, Talei A-R, Banani SJ. Analysis of BRCA1 and BRCA2 mutations in southern Iranian breast cancer patients. Arch Iran Med. 2009;12(6):584-7.

15.Bruchim Bar-Sade R, Kruglikova A, Modan B, Gak E, HirshYechezkel G, Theodor L, et al. The 185delAG BRCA1 mutation originated before the dispersion of Jews in the diaspora and is not limited to Ashkenazim. Hum Mol Genet. 1998;7(5):801-5.

16.Mehdipour P, Hosseini-Asl S, Savabi-E A, Habibi L, Alvandi E, Atri $M$. Low frequency of 185delAG founder mutation of BRCA1 gene in Iranian breast cancer patients. J Cancer Mol. 2006;2(3):123-7.

17.Rassi H, Gorovenko N, Houshmand M, Podolskaya S, Hashemi M, Majidzadeh K, et al. Application of multiplex PCR with histopathologic features for detection of familial breast cancer in formalin-fixed, paraffin-embedded histological specimens. Cytol Genet. 2008;42(2):120.

18.Yassaee VR, Zeinali S, Harirchi I, Jarvandi S, Mohagheghi MA, Hornby DP, et al. Novel mutations in the BRCA1 and BRCA2 genes in Iranian women with early-onset breast cancer. Breast Cancer Res. 2002;4(4):R6.

19.Saleh-Gohari N, Mohammadi-Anaie M, Kalantari-Khandani B. BRCA1 gene mutations in breast cancer patients from Kerman Province, Iran. Iran J Cancer Prev. 2012;5(4):210.

20.Keshavarzi F, Javadi GR, Zeinali S. BRCA1 and BRCA2 germline mutations in 85 Iranian breast cancer patients. Fam Cancer. 2012;11(1):57-67.

21.Pietschmann A, Mehdipour P, Atri M, Hofmann W, Hosseini-Asl SS, Scherneck S, et al. Mutation analysis of BRCA1 and BRCA2 genes in Iranian high risk breast cancer families. J Cancer Res Clin Oncol. 2005;131(8):552-8.

22.Meisel C, Sadowski CE, Kohlstedt D, Keller K, Stäritz F, Grübling $\mathrm{N}$, et al. Spectrum of genetic variants of BRCA1 and BRCA2 in a German single center study. Arch Gynecol Obstet. 2017;295(5):122738.

23.Ghaderi A, Talei A, Farjadian S, Mosalaei A, Doroudchi M, Kimura H. Germline BRCA1 mutations in Iranian women with breast cancer. Cancer Lett. 2001;165(1):87-94.

24.Seo JH, Cho DY, Ahn SH, Yoon KS, Kang CS, Cho HM, et al BRCA1 and BRCA2 germline mutations in Korean patients with sporadic breast cancer. Hum Mutat. 2004;24(4):350-.

25.Mundhofir FE, Wulandari CE, Prajoko YW, Winarni TI. BRCA1 Gene Mutation Screening for the Hereditary Breast and/or Ovarian Cancer Syndrome in Breast Cancer Cases: a First High Resolution DNA Melting Analysis in Indonesia. Asian Pac J Cancer Prev. 2016;17(3):1539-46.

26.Zhu Y, Kan Zhai JK, Li J, Gong Y, Yang Y, Tian J, et al. BRCA1 missense polymorphisms are associated with poor prognosis of pancreatic cancer patients in a Chinese population.Oncotarget. 2017;8(22):36033.

27.Teng LS, Zheng Y, Wang HH. BRCA1/2 associated hereditary breast cancer. J Zhejiang Uni Sci B. 2008;9(2):85-9.

28.Zanella I, Merola F, Biasiotto G, Archetti S, Spinelli E, Di Lorenzo D. Evaluation of the Ion Torrent PGM sequencing workflow for the routine rapid detection of BRCA1 and BRCA2 germline mutations. Exp Mol Pathol. 2017;102(2):314-20.

29.Madjd Z, Ramezani B, Molanae S, Asadi-Lari M. High expression of stem cell marker ALDH1 is associated with reduced BRCA1 in invasive breast carcinomas. Asian Pac $\mathrm{J}$ Cancer Prev. 2012;13(6):2973-8. 